\title{
CREB antisense oligodeoxynucleotide administration into the dorsal hippocampal CA3 region impairs long- but not short-term spatial memory in mice
}

\author{
Cédrick Florian, ${ }^{1}$ Nicole Mons, ${ }^{2}$ and Pascal Roullet ${ }^{1,3}$ \\ ${ }^{1}$ Centre de Recherches sur la Cognition Animale, Centre National de la Recherche Scientifique, Unité Mixte de Recherche \\ (CNRS UMR) 5169, Université Paul Sabatier, 31062 Toulouse cedex 9, France; ${ }^{2}$ Laboratoire de Neurosciences Cognitives, \\ CNRS UMR 5106, 33405 Talence cedex, France
}

\begin{abstract}
The transcription factor cAMP response-element binding protein (CREB) has a pivotal role in hippocampal synaptic plasticity and hippocampus-dependent long-term memory. We recently demonstrated that the dorsal hippocampal CA3 region is involved in memory consolidation of spatial information tested on a Morris water maze in mice. To test whether activation of CREB in the CA3 region is required for memory consolidation of spatial information, bilaterally cannulated mice were infused $18 \mathrm{~h}$ before the beginning of the behavioral training with antisense or control sense CREB oligodeoxynucleotides (ODNs) or buffer. Mice were then subjected to massed training in a spatial version of the water maze and tested for retention 0 or $24 \mathrm{~h}$ after the last training session. We showed that CREB antisense ODN-infusion in the CA3 region impaired long-term memory when tested $24 \mathrm{~h}$ later but had no effect on spatial acquisition or short-term memory tested immediately after behavioral training. These findings provide evidence that the regionally restricted activation of CREB in the dorsal hippocampal CA3 region is critical for the long-term memory consolidation phase of spatial learning but not for short-term memory.
\end{abstract}

Many investigators have demonstrated the involvement of the CA3 region in spatial working memory (Frederickson et al. 1990; Lee and Kesner 2002, 2003), in the initial acquisition phase of spatial learning (Handelmann and Olton 1981; Lassalle et al. 2000), and during consolidation of memory for nonassociative (Stupien et al. 2003) and associative spatial learning tasks (Zhao et al. 2000). Previously, we showed that CA3 integrity is important for spatial encoding and particularly for memory consolidation of spatial information in the Morris water maze (MWM) task (Florian and Roullet 2004). Thus, it has been proposed that the CA3 region plays an important role in the formation of longterm memory (LTM) and the regulation of hippocampal synaptic activity during learning and memory. It has become widely accepted that LTM formation requires activation of gene transcription (Alberini et al. 1994; Bailey et al. 1996; Guzowski et al. 2001; Bozon et al. 2002) and de novo protein synthesis (Davis and Squire 1984; Bourtchouladze et al. 1998; Quevedo et al. 1999). A principal candidate, the transcription factor cAMP responseelement binding protein (CREB), plays a prominent role in plasticity processes underlying learning and LTM (Frank and Greenberg 1994; Carew 1996; Silva et al. 1998). Indeed, phosphorylation of CREB (pCREB) in the nucleus plays an essential role in downstream transcriptional regulation of proteins required for LTM in a variety of species. It has been shown that disruption of CREB function in invertebrates selectively blocks long-term synaptic changes and LTM (Dash et al. 1990; Yin et al. 1994; Bartsch et al. 1995) whereas injection of CRE-containing promoter induced CREB activation and long-term facilitation (Kaang et al. 1993). Further, in rodents, suppression of CREB signaling by local administration of CREB antisense oligodeoxynucleotides (ODNs) into the dorsal hippocampus or the amygdala reduced CREB protein levels and disrupted the late consolidation of spatial memory (Guzowski and McGaugh 1997) and the LTM for con-

\footnotetext{
${ }^{3}$ Corresponding author.
}

E-mail roullet@cict.fr; fax 33-05-61-55-61-54.

Article is online at http://www.learnmem.org/cgi/doi/10.1101//m.249306. ditioned taste aversion (Lamprecht et al. 1997). Furthermore, mice lacking the $\alpha$ and $\Delta$ isoforms of CREB showed significantly impaired hippocampus-dependent LTM as well as deficient hippocampal long-term potentiation (LTP) (Bourtchouladze et al. 1994). Together, these findings indicate that CREB, by acting as a "memory modulator" (Yin et al. 1995), is essential for consolidation processes of LTP and the formation of LTM in multiple tasks and many species.

The purpose of the present study was to examine whether the regionally restricted activation of CREB in the hippocampal CA3 region is required for consolidation of spatial memory. Therefore, pre-training local infusion of antisense ODNs directed against CREB mRNA was performed. Mice received massed training in the spatial version of the MWM and tested for retention either 0 or $24 \mathrm{~h}$ after training.

\section{Results}

CREB antisense ODN infusion had no effect on acquisition of spatial information in the MWM

We examined the effect of either CREB antisense (AS-ODN) or sense (S-ODN) or PBS treatment in the CA3 region on acquisition of spatial position of hidden platform. Figure 1 illustrates the mean of path length swam before escape onto the hidden platform across the four learning sessions for each group. A two-way ANOVA, revealed a significant session effect $\left(F_{(3,174)}=33.040\right.$, $P<0.001)$ but no treatment effect $\left(F_{(2,58)}=1.208, P=0.306\right)$ and no significant interaction between these two factors $\left(F_{(6,174)}=1.074\right.$, $P=0.380)$. This indicates that CREB AS-ODN infusion given $18 \mathrm{~h}$ before training did not affect the capacity to acquire a fixed goal location across massed learning sessions.

After learning sessions, mice were randomly divided into two experimental groups to test the importance of CREB in the CA3 region for spatial short-term memory (STM) and LTM formation. Bilaterally cannulated mice were submitted to the probe test either immediately (STM group) or $24 \mathrm{~h}$ (LTM group) after the learning phase. 


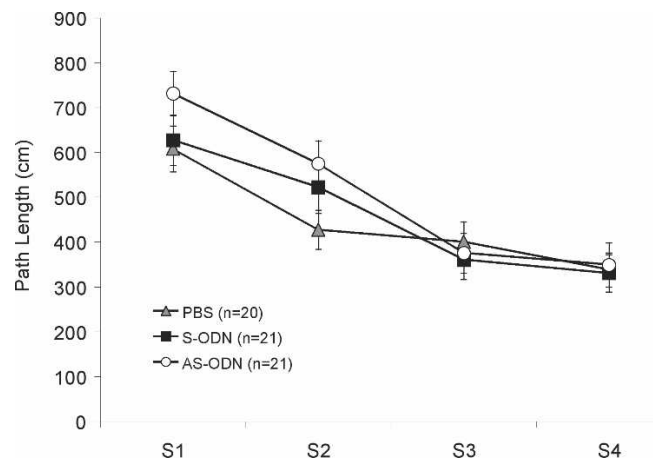

Figure 1. Mean path length to find the platform during the training phase of the spatial water maze task. Mice received bilateral intrahippocampal injection of PBS, S-ODN, and AS-ODN (4 nmol/0.25 $\mu \mathrm{L} / \mathrm{side})$ $18 \mathrm{~h}$ before the first training session $\mathrm{S} 1$.

\section{CREB antisense injection had no effect on spatial short-term memory}

Figure 2 shows the time spent (A) and the number of annulus crossings (B) in the four quadrants by PBS-injected, S-ODNinjected, and AS-ODN-injected mice in the STM probe test. A one-way ANOVA showed no effect of treatment on the time spent in the target quadrant $\left(F_{(2,24)}=0.562, P=0.577\right)$. Moreover, a two-way ANOVA performed on the number of annulus crossings revealed no treatment effect $\left(F_{(2,92)}=0.491, P=0.613\right)$, a significant quadrant effect $\left(F_{(3,92)}=38.384, P<0.001\right)$, and no treatment $\times$ quadrant interaction $\left(F_{(6,92)}=1.007, P=0.426\right)$. For
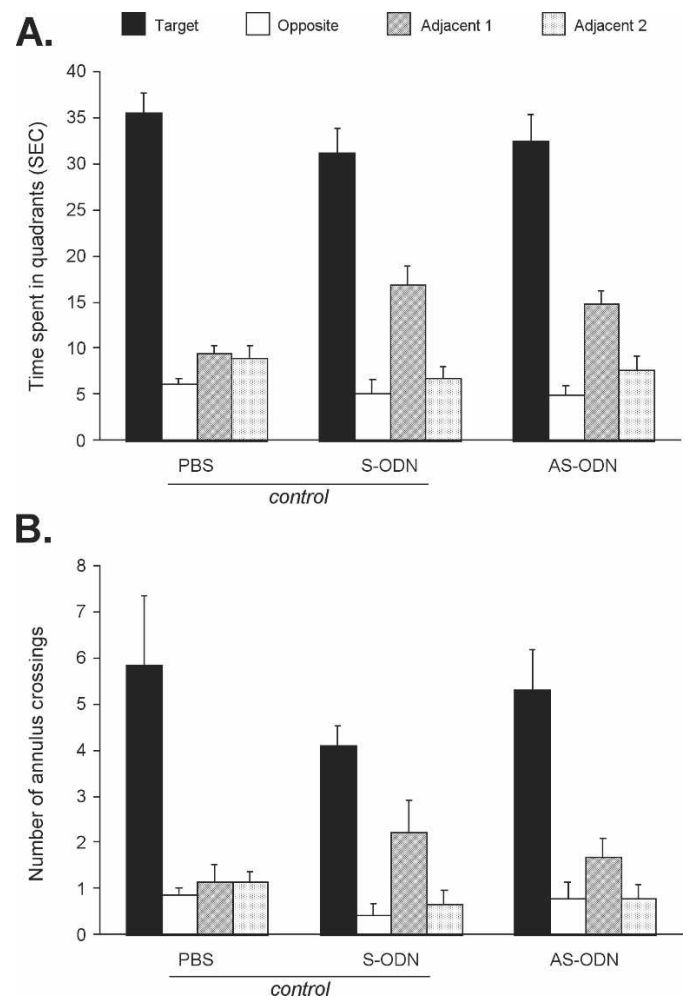

Figure 2. Short-term memory. Effect of PBS $(n=8)$, S-ODN $(n=9)$, and AS-ODN $(n=10)$ administration on immediate post-training probe trial performance in the spatial water maze task. $(A)$ Histograms represent time (seconds) spent in the four quadrants of the pool. (B) Number of annulus crossings during the 60 -sec probe trial performed immediately after training. the number of annulus crossings in the target quadrant, there was no general treatment effect $\left(F_{(2,23)}=0.858, P=0.431\right)$ and therefore no effect of AS-ODN injection (AS-ODN vs. PBS: $F_{(1,15)}=1.414, P=0.256$; AS-ODN vs. S-ODN: $F_{(1,16)}=0.495$, $P=0.492)$

Figure $3 \mathrm{~A}$ shows the spatial index, calculated on the basis of annulus crossings during the probe test. A one-way ANOVA that compared the spatial index across all groups indicated that there was no treatment effect $\left(F_{(2,24)}=0.113, P=0.894\right)$, indicating that the spatial index was similar in the three groups. Additional analyses did not reveal any significant difference between PBSinfused, S-ODN- infused, and AS-ODN-infused mice in swimming speed $\left(F_{(2,24)}=1.774, P=0.191\right)$ or on the time spent in the periphery of the pool during the probe test $\left(F_{(2,24)}=0.485\right.$, $P=0.622$ ) (Table 1$)$. Together, these results suggest that CREB AS-ODN infusion in the CA3 region did not induce thigmotaxis or particular problems in locomotor activity. Hence, as shown in Figure 3B, during STM memory trial all groups of mice spent more time in the target quadrant than in the other quadrants, suggesting that infusion of CREB AS-ODN in the CA3 region did not affect spatial STM.

\section{CREB antisense injection impaired the spatial long-term performances}

We next examined the effect of either CREB AS-ODN or S-ODN or PBS injection into the CA3 region on LTM formation. As shown in Figure 4, infusion of CREB AS-ODN in the CA3 region decreased long-term retention at $24 \mathrm{~h}$ compared with S-ODNinjected or PBS-injected groups. An ANOVA revealed that there was a marginal effect on time spent in the target quadrant between PBS-injected, S-ODN-injected and AS-ODN-injected mice $\left(F_{(2,32)}=3.124, P=0.058\right)$. Post hoc analysis showed that the PBS-injected group spent more time in the target quadrant than did the AS-ODN group $(P<0.05)$ (Fig. 4A). For the number of annulus crossings (Fig. 4B), there was no treatment effect $\left(F_{(2,128)}=0.192, P=0.826\right)$, but a significant quadrant effect $\left(F_{(3,128)}=42.972, P<0.001\right)$ and a significant quadrant $\times$ treat-

A. Short-term memory

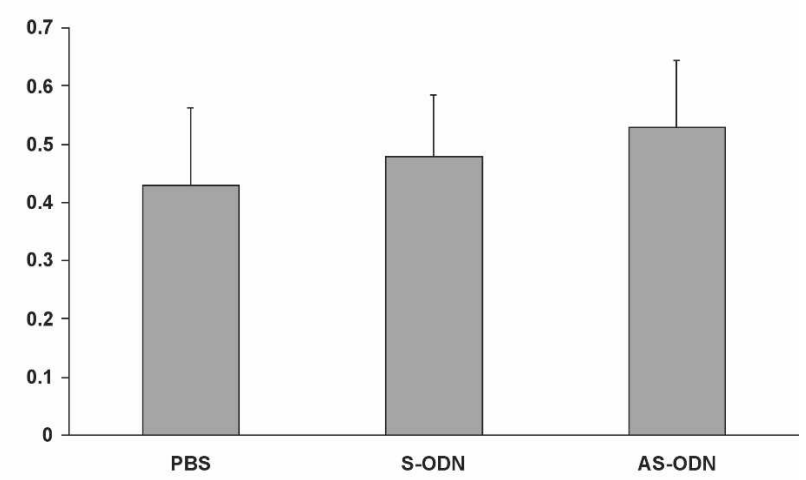

B.
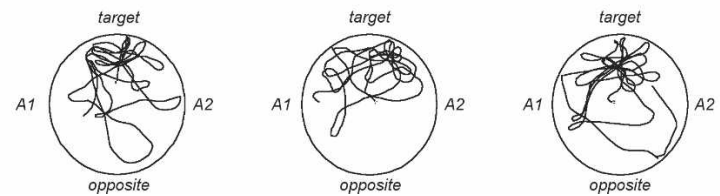

Figure 3. (A) The histograms represent the spatial index, calculated as the difference between the number of target annulus crossings over the expected position of the platform and the mean number of crossings of the three remaining annuli, divided by the total number of annulus crossings, during the immediate probe trial. (B) Representative paths taken by animals treated with (left to right) PBS, S-ODN, or AS-ODN. 
Table 1. Thigmotactic behavior and swimming speed parameters during spatial Morris water maze probe trial in PBS-injected, S-ODN-injected and AS-ODN-injected C57bl/6 mice

\begin{tabular}{|c|c|c|c|c|c|c|}
\hline & \multicolumn{2}{|c|}{ PBS } & \multicolumn{2}{|c|}{ S-ODN } & \multicolumn{2}{|c|}{ AS-ODN } \\
\hline & Periphery area & Swimming speed & Periphery area & Swimming speed & Periphery area & Swimming speed \\
\hline $\begin{array}{l}\text { Short-term memory } \\
\text { Long-term memory }\end{array}$ & $\begin{array}{l}20.45 \pm 2.76 \\
20.50 \pm 3.05\end{array}$ & $\begin{array}{l}18.1 \pm 0.5 \\
16.3 \pm 1.0\end{array}$ & $\begin{array}{l}18.60 \pm 2.86 \\
14.63 \pm 2.48\end{array}$ & $\begin{array}{l}15.7 \pm 0.8 \\
18.2 \pm 1.0\end{array}$ & $\begin{array}{l}16.78 \pm 2.28 \\
20.05 \pm 3.12\end{array}$ & $\begin{array}{l}16.7 \pm 1.1 \\
18.5 \pm 0.9\end{array}$ \\
\hline
\end{tabular}

Data show the average time (in seconds) spent in the periphery of the maze pool (a 13-cm-wide wall zone) and the average swimming speed (cm/sec) during the 60 -sec probe trial conducted $0 \mathrm{~h}$ (short-term memory) or $24 \mathrm{~h}$ (long-term memory) after training. All infusions ( $0.25 \mathrm{hL} / \mathrm{side}$ ) were performed $18 \mathrm{~h}$ before the first training session.

ment interaction $\left(F_{(6,128)}=2.833, P=0.013\right)$. Post hoc comparison showed a significant difference between the target quadrant and the other three quadrants for control animals $(P \mathrm{~s}<0.001)$ and for the S-ODN group ( $P s<0.01)$ but not for AS-ODN-treated mice $(P \mathrm{~s}>0.3)$. Moreover, the analysis between the target quadrants reveals a general treatment effect $\left(F_{(2,32)}=3.416, P=0.045\right)$ due to the AS-ODN injection (AS-ODN vs. PBS: $F_{(1,21)}=5.817$, $P=0.025$; AS-ODN vs. S-ODN: $\left.F_{(1,21)}=5.166, P=0.034\right)$. In addition, Figure $5 \mathrm{~A}$ shows a significant difference in the spatial index between the three groups $\left(F_{(2,32)}=10.06, P<0.001\right)$, which was attributable to the AS-ODN injection. A significant difference was observed between the AS-ODN-infused mice and the two other groups (AS-ODN vs. PBS: $F_{(1,21)}=26.821, P<0.001$; ASODN vs. S-ODN: $\left.F_{(1,21)}=10.157, P<0.01\right)$. In contrast, ANOVA failed to reveal any difference in swimming speed parameter $\left(\mathrm{F}_{(2,32)}=1.596, P=0.218\right)$ or on the time spent in the maze periphery $\left(F_{(2,32)}=1.301, P=0.286\right)$ between AS-, $S-$, and PBSinfused mice in the LTM probe trial (Table 1). Together, these results suggest that infusion of CREB AS-ODN affects long-term retention performance (Fig. 5B) and, specifically the precision of the search for the platform without affecting motor or motivational/emotional processes.

\section{CREB antisense reduced the level of $\mathrm{PCREB}$ protein into the hippocampal $\mathrm{CA} 3$ region}

Activation of CREB through Ser133 phosphorylation constitutes a crucial step in the molecular machinery involved in the conversion of short- to LTM (for review, see Mayford and Kandel 1999). To determine whether deficits in long-term spatial learning correlate with reduced PCREB level in the CA3 region and whether this reduction is specific to this region, we examined the pCREB level after infusion of CREB antisense ODN into CA3. As for rostrocaudal diffusion (Fig. 6), all the retained mice had the tip of the injection cannulae between bregma $-1.46 \mathrm{~mm}$, and bregma $-1.94 \mathrm{~mm}$, and the area affected by the injection did not exceed $600 \mu \mathrm{m}$ in diameter. As is shown in Figure 7A, the mediolateral diffusion of the CREB AS-ODN is restricted to the dorsal CA3 region and did not diffuse into the other hippocampal subfields (CA1-region and dentate gyrus). When animals were injected with CREB AS-ODN in the CA3-region, the level of pCREB signal was significantly reduced in the area surrounding the injection site (Fig. 7A,C,D), without affecting pCREB levels in the other hippocampal subfields, indicating that the effect of CREB AS-ODN displayed anatomical site specificity for CA3. A two-way ANOVA for PCREB in the CA1-region or the dentate gyrus revealed no significant treatment effect (S-ODN trained vs. AS-ODN trained), no delay effect $(0$ vs. 24 h) or treatment $\times$ delay interaction (all $F \mathrm{~s}<1$; all $P \mathrm{~s}>0.2$ ), indicating that the diffusion of CREB AS-ODN was restricted to the CA3 region. In contrast, a two-way ANOVA for pCREB in the CA3 region revealed significant main effects for treatment $\left(F_{(3,31)}=38.306\right.$, $P<0.001)$ and delay $\left(F_{(1,31)}=100.014, P<0.001\right)$, as well as a significant treatment $\times$ delay interaction $\left(F_{(3,31)}=48.166\right.$,
$P<0.001)$. Post hoc analysis indicated that the level of pCREB in naive AS-ODN-injected mice was similar to the naive S-ODNtreated mice at $0 \mathrm{~h}$ and $24 \mathrm{~h}$ post-training (Fig. 7D). Moreover, mice subjected to massed training in the water maze had significantly more pCREB in the CA3 region than did naive mice (SODN naive vs S-ODN trained, $P<0.01)$, and this training effect remained significant for at least $24 \mathrm{~h}(P<0.001)$. When compared with S-ODN-infused mice, Figures 7C,D show that AS-ODN infusion significantly reduced the level of pCREB by $86 \%$ immediately after massed training (AS-ODN trained vs. S-ODN trained, $P<0.001)$. In comparison with naive mice, AS-ODN infusion only reduced the pCREB level by $44 \%$, but this decrease was non significant $(P=0.76)$. However, when immunohistochemical analysis was performed $24 \mathrm{~h}$ after behavioral training, levels of pCREB in the CA3 region were no longer decreased in AS-ODNinfused mice (AS-ODN trained vs. S-ODN trained, $P=0.97$ ), indicating that the effect of CREB AS-ODN was time-limited.
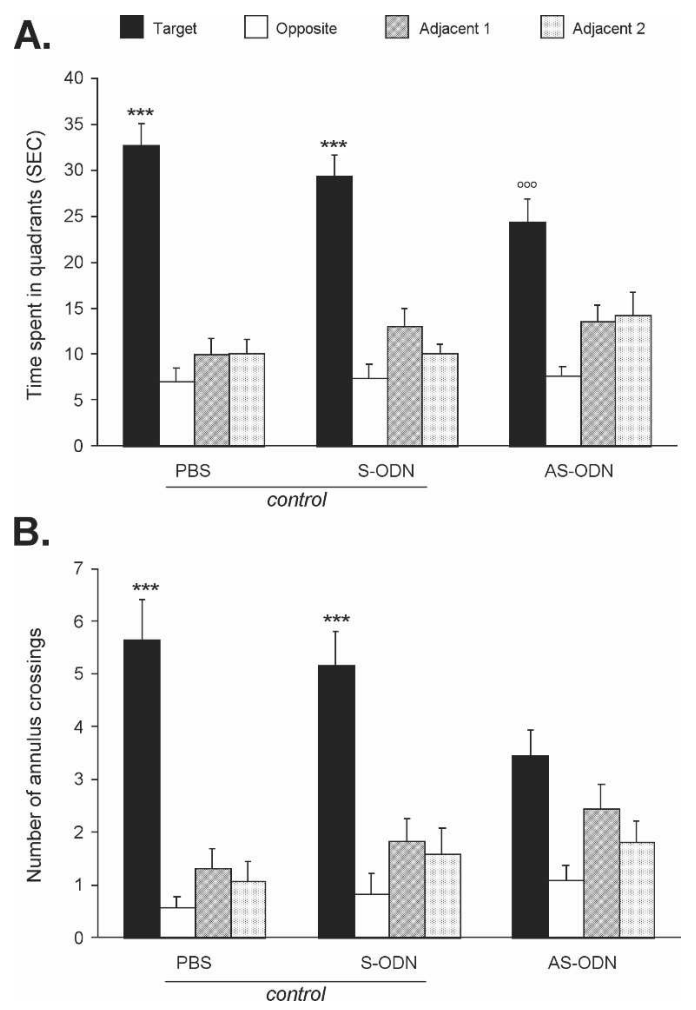

Figure 4. Long-term memory. Effect of PBS $(n=12)$, S-ODN $(n=12)$, and AS-ODN $(n=11)$ administration on $24 \mathrm{~h}$ post-training probe trial performance in the spatial water maze task. $(A)$ Histograms represent time (seconds) spent in the four quadrants of the pool. (B) Histograms represent the number of annulus crossings during the 60 -sec probe trial performed $24 \mathrm{~h}$ after training. ${ }^{* * *} P<0.001$, target vs. opposite, adjacent 1 and 2 quadrants within groups; ${ }^{\circ 00} p<0.001$, target vs. opposite. 
A.

Long-term memory

B.
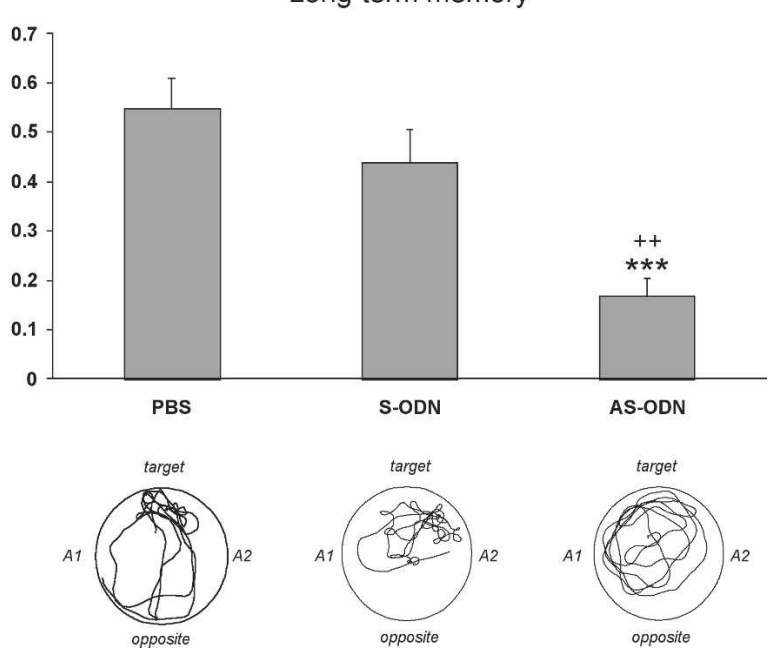

Figure 5. (A) The histograms represent the spatial index, calculated as the difference between the number of crossings of the annulus surrounding the expected position of the platform and the mean number of crossings of the three remaining annuli, divided by the total number of annulus crossings, during the $24-\mathrm{h}$ probe trial. (B) Representative paths taken by animals treated with (left to right) PBS, S-ODN, or AS-ODN ${ }^{* * *} P<0.001$, AS-ODN vs. PBS group; ${ }^{++} P<0.01$, AS-ODN vs. S-ODN.

\section{Discussion}

The main findings of the present study are that the local infusion of CREB AS-ODN in the dorsal hippocampal CA3 region $18 \mathrm{~h}$ before training affected LTM retention in the spatial water maze task but did not block immediate STM. This is the first evidence that a local activation of CREB in the CA3 region is critically involved in the consolidation of spatial memory for MWM training and reinforces the notion that activation of the CREB signaling pathway is a critical component of hippocampal-dependent memory consolidation processes.

To investigate the role of CREB expression in spatial memory formation in the CA3-region, we used a spatial behavioral massed-procedure of four training sessions (12 trials) in a short period of time (within a 2 -h period). In this procedure, we observed that animals were able to locate the hidden platform position across all the training sessions. During the probe test performed either 0 or $24 \mathrm{~h}$ after the training sessions, mice searched for the platform in the quadrant where it was located during the acquisition phase, suggesting that mice adopted a spatial strategy to find it. Hence, our massed procedure allowed us to study post-training events occurring during the early memory consolidation phase (Sargolini et al. 2003; Florian and Roullet 2004)

Our experiments showed that intra-CA3 infusion of CREB AS-ODN did not affect spatial acquisition and did not affect STM. This AS-ODN injection specifically affected LTM for spatial memory in the water maze, and this deficit seems more important for annulus crossings than for the time spent in quadrants. Indeed, AS-ODN-injected mice spent more time in the target area compared with the opposite quadrant, but they extended their search to the adjacent quadrants. This indicates that these mice always knew approximately where the platform was but then were not able to locate the exact position of the platform. So, AS-ODN injection induced a clear impairment of the spatial LTM. It has been previously reported that disruption of hippocampal CRE-dependent gene expression in the dorsal hippocampus, either by pre-training infusion of CREB AS-ODN (Guzowski and McGaugh 1997) or by using transgenic mice carrying K-CREB
(Pittenger et al. 2002), significantly impaired spatial long-term retention performance in the water maze task. Balschun et al. (2003) reported that CREB has a minor function in hippocampal long-term synaptic plasticity and LTM, and that deficits in water maze learning in CREB mutant mice are predominantly due to a marked increase in wall hugging (thigmotaxis). This is not consistent with our present results because all mice from the CREB AS-ODN and S-ODN or PBS control groups were indistinguishable in both swimming speed and time spent in the periphery, measured during acquisition and the immediate and 24-h probe trials. One explanation for these discrepancies is the different approaches used to inactivate CREB protein function in the two studies. In Balschun et al.'s studies, the investigators used conditional knock-out mice and the reduction in CREB by gene targeting could trigger an upregulation of cAMP response element binding modulator (CREM), which may compensate for many functional deficits. Another explanation is that disruption of CREB in CA1 neurons versus CA3 region could account for these discrepancies. Finally, these investigators used a spaced training protocol over $14 \mathrm{~d}$, whereas in our study, mice were submitted to a massed learning protocol in order to test the role of CREB only in the first memory consolidation phase. In the present experiment, deficits in the CREB AS-ODN mice were caused specifically by a lack of memory capacities during the spatial long-term retrieval. More precisely, in these experiments, the level of pCREB is decreased during the learning phase and the memory consolidation but not $24 \mathrm{~h}$ later during the retrieval phase. Thus, the observed effect during the probe test cannot be due to the action of this ODN injection during learning because acquisition and STM are normal in CREB AS-ODN-injected mice. Also, it is not possible to explain this decrease of performance by an effect of AS-ODN during the recall phase because the level of pCREB is normal. Therefore, the only possible explanation is that CREB AS-ODN blocked the memory consolidation phase.

Increasing evidence suggests that LTM formation and longlasting synaptic plasticity require activation of the CREBsignaling cascade and induction of CRE-dependent transcriptional events in invertebrates as well as in rodents (Bourtchouladze et al. 1994; Impey et al. 1996; for a review, see Josselyn and NGuyen 2005). Indeed, several studies support the hypothesis that CREB phosphorylation, in a specific and highly localized manner, is involved in protein synthesis-dependent LTM in diverse learning paradigms among many species (for a review, see Josselyn and NGuyen 2005). Moreover, CREB is a target of a

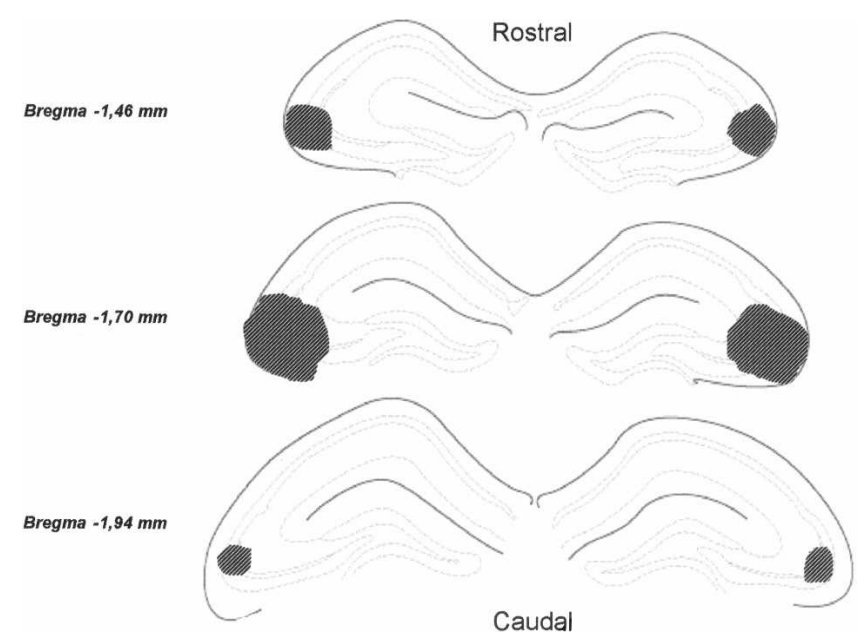

Figure 6. Schematic representations of the extent of the bilateral ODN microinfusions into the CA3 hippocampal subfield. 


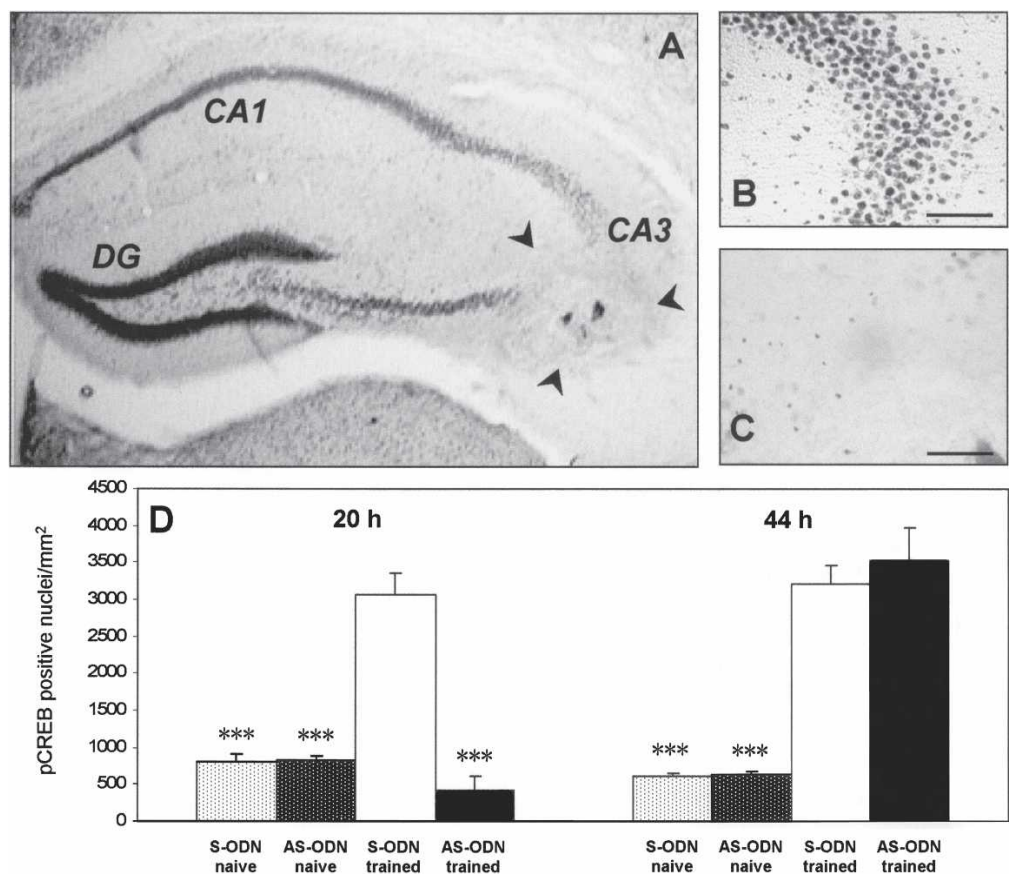

Figure 7. Microinjection of CREB antisense oligodeoxynucleotide (AS-ODN) into the dorsal hippocampal CA3 region $(A)$ and reduction of pCREB positive nuclei by CREB antisense $(C, D)$. (A) Image recorded immediately after the training phase and the immunochemistry analysis (for details, see Materials and Methods). Arrowheads represent the edge of the microinjection. Immunochemistry of pCREB using PCREB antibodies in mice receiving an injection of CREB sense $(B)$ and antisense $(C)$ Scale bar, $100 \mu \mathrm{m}$. (D) Number of pCREB-positive nuclei in the CA3 region of mice receiving an injection of CREB antisense (AS-ODN trained/naive) versus CREB sense (S-ODN trained/naive) at 0 and $24 \mathrm{~h}$ post-training. The asterisks indicate the significant difference with S-ODN trained; ${ }^{\star * \star} P<0.001$.

number of cAMP- and $\mathrm{Ca}^{2+}$-regulated signaling kinases, including mitogen-activated protein kinase, protein kinase $\mathrm{B}$, and calcium-calmodulin-dependent protein kinases (Deisseroth et al. 1996; Gonzales and Montminy 1989; Impey et al. 1996). Phosphorylation/activation of CREB on Ser-133 stimulates the expression of immediate-early genes, such as $c$-fos and zif 268 , which are required for consolidation of memory (Hardingham et al. 2001; Athos et al. 2002). CREB AS-ODN has been previously shown to prevent CREB synthesis and ensuing CREB activation (Guzowski and McGaugh 1997; Zhang et al. 2003). However, only pCREB is capable of activating gene transcription (Bito et al. 1996), suggesting that CREB phosphorylation is essential for spatial memory consolidation.

In this present experiment, we showed that the regionally restricted activation of CREB in the hippocampal CA3 region is critical for spatial LTM in the MWM. In accordance with our results, an induction of CREB phosphorylation into the dorsal hippocampal CA3 region has been shown after spatial learning in the cross maze task (Colombo et al. 2003). Taken together, these data indicate that CREB activation in this subfield is required for spatial LTM formation. However, an induction of CREB phosphorylation in the CA3 region has been also reported after nonspatial learning (Saha and Datta 2005). In accord with the role of CREB signaling in CA3 region in LTM formation, a selective induction of $c$-fos in this CA3 region during the consolidation processes has previously been demonstrated (Bertaina-Anglade et al. 2000; He et al. 2002).

In the CA3 region, three major afferents (the mossy fiber of the dentate gyrus, the perforant path, and the recurrent collateral of the CA3 pyramidal cells) terminate on the same apical dendrites, forming a complicated laminar network (Amaral and Witter 1995). Based on this evidence, a number of computational agree with the different theories on the CA3 functions cited above. Indeed, blocking CREB activity, as in blocking the NMDA receptors, in the CA3 region during memory consolidation almost certainly prevents recurrent fiber synapses from being modified and strengthened to reinforce the pattern of CA3 ensemble.

\section{Materials and Methods}

\section{Animals}

A total of 99 male and female C57BL/6 inbred mice bred in our laboratory were used in these studies. After birth, they remained with their parents until weaning at $21 \mathrm{~d}$ of age. They were then placed in groups of three to six animals of the same sex and age in standard breeding cages placed in a rearing room at a constant temperature $\left(23 \pm 1^{\circ} \mathrm{C}\right)$ with food and water ad libitum. At the time of surgery, they were 90-120 d old. They were tested during the first half of their light period (between 9:00 a.m. and 12:30 p.m.). Every possible effort was made to minimize animal suffering, and all procedures were in strict accordance with European community and French national laws and regulations on the use of animals in research and NIH guidelines on animal care.

\section{Surgery}

Guide cannulae ( $0.56 \mathrm{~mm}$ in diameter) were implanted bilaterally $1.2 \mathrm{~mm}$ above the CA3 region and fixed on the calvarium with dental cement. The following coordinates with lambda and bregma in the same horizontal plane were used: posterior to bregma, $-1.6 \mathrm{~mm}$; lateral to midline, $\pm 2.5 \mathrm{~mm}$; and $1.5 \mathrm{~mm}$ beneath the skull surface, according to the method of (Franklin and Paxinos 1997). The subjects were then left in their home cages for a recovery period of 7-8 $\mathrm{d}$. 


\section{ODN infusion procedure}

The unmodified ODNs were synthesized by the MWG Biotech AG. The sequences of the CREB antisense (AS-ODN) and sense (S-ODN) were as follows: 5'-TGGTCATCTAGTCACCGGTG-3' and 5'-CACCGGTGACTAGATGACCA-3' (Guzowski and McGaugh 1997). The stylus was removed from the guide cannulae, and an injection needle $(0.28 \mathrm{~mm}$ in diameter) was inserted into the guide cannula. Microinjection of either AS-ODN or S-ODN (4 nmol resuspended in $0.25 \mu \mathrm{L}$ phosphate buffer $[\mathrm{PB}]$ saline [PBS]/hemisphere for AS- and S-ODN) or PBS alone was performed $18 \mathrm{~h}$ before the training period. Infusions were delivered over 150 sec using a 1- $\mu \mathrm{L}$ Hamilton syringe driven by a microinjection pump (Bioblock Scientific, Razel Scientific Instrument) at a rate of $0.1 \mu \mathrm{L} / \mathrm{min}$. The needle was left in place for an additional $60 \mathrm{sec}$ to allow diffusion. All mice remained in their home cages during the injection time.

\section{MWM apparatus}

The MWM was a swimming circular pool, $110 \mathrm{~cm}$ diameter and $30 \mathrm{~cm}$ high, filled to a depth of $15 \mathrm{~cm}$ with water temperature maintained at $23 \pm 1^{\circ} \mathrm{C}$. The surface water was made opaque by addition of a white nontoxic opacifier (Opacifier 631). A whitepainted platform $(9 \mathrm{~cm}$ in diameter) was placed inside the pool, $15.5 \mathrm{~cm}$ away from the pool wall. Several extramaze visual cues, $\sim 50-100 \mathrm{~cm}$ away from the pool, were attached to the walls of the experimental room. Four start positions were located around the perimeter of the pool, dividing its surface into four equal quadrants. The swimming pool was visible by a video camera connected to a video recorder and a monitor.

\section{Spatial behavioral procedure}

We used a massed training procedure in the spatial MWM as described in the Figure 8 (Sargolini et al. 2003; Florian and Roullet 2004). Briefly, on day 0, mice were placed in the experimental room for $15 \mathrm{~min}$ and were then individually submitted to a single pre-training session consisting of three trials with a visible platform that protruded $0.5 \mathrm{~cm}$ above the surface of the water and was always located in the same quadrant. The session started with the mouse standing on the platform for $60 \mathrm{sec}$. At the beginning of each trial, mice were placed in the maze facing the wall at one of the different starting locations. They were allowed to swim freely until they reached the platform. Any mouse that did not find the platform within $60 \mathrm{sec}$ was gently guided to it by the experimenter. After the animals had climbed onto the platform, they were allowed to remain on it for an additional $60 \mathrm{sec}$ and were subsequently replaced in the maze from a different starting location. The starting positions were determined in a pseudorandom order, such that each was used once in a single session.

Twenty-four hours later (day 1), mice received a series of four consecutive sessions of three trials with a 15- to 20-min intertrial interval. The procedure was the same as in the pretraining phase, except the platform was submerged $0.5 \mathrm{~cm}$ beneath the surface of the water. The mice were allowed to navigate to the hidden platform using the spatial cues available in the room. At the completion of each session, mice were removed from the platform and placed in their home cage. For testing STM and LTM, a single-trial probe test was conducted immediately after the last training session (day 1) or $24 \mathrm{~h}$ later (day 2), respectively. During the probe test, the platform was removed and mice, starting from the center of the pool, were allowed a 60 -sec search for the platform.

After behavioral testing, mice $(n=76)$ were sacrificed, and brains were removed, fixed in 10\% glutaraldehyde/30\% sucrose solution, and sectioned on a freezing microtome. Cannulae placements were determined by examination of serial coronal sections $(40 \mu \mathrm{m})$ stained with thionine. Serial sections were subjected to binocular microscopic inspection with high magnification $(40 \times)$, and mice in which infusion of ODN overflowed into the CA1 or CA4 regions were removed from the statistic analysis.

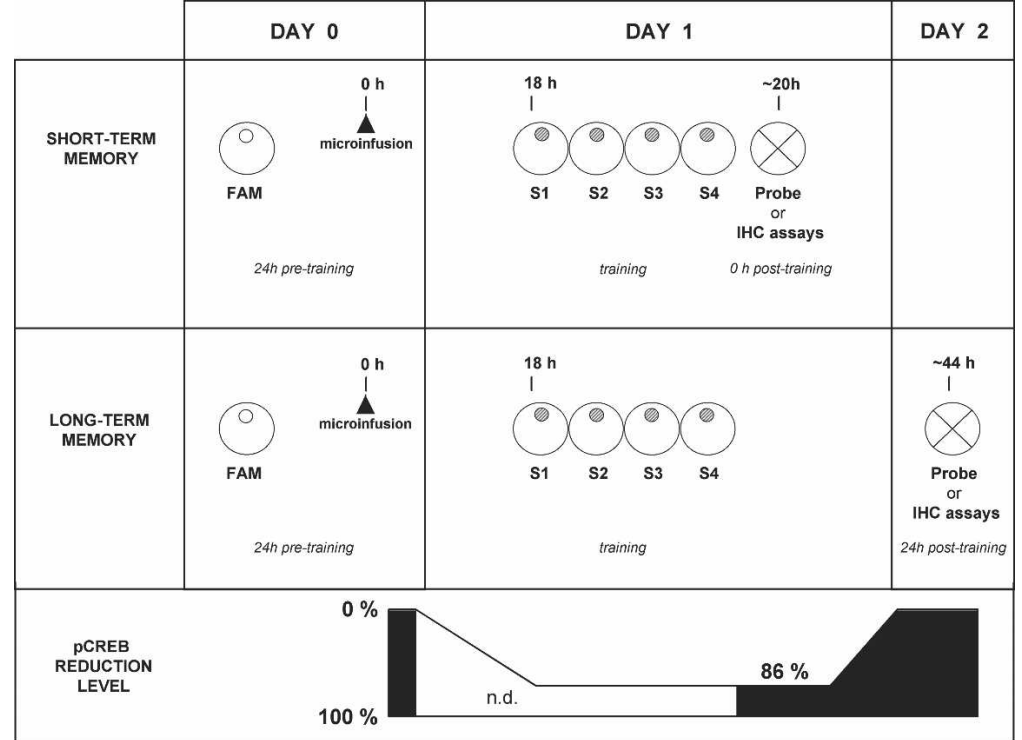

Figure 8. Behavioral experimental design for testing short- and long-term memory. After a pretraining period (day 0 ), in which mice were submitted to the visible platform version of the Morris water maze, mice received an injection of either AS-ODN, S-ODN, or PBS. Eighteen hours after infusion (day 1), mice were submitted to four massed learning sessions (S1-S4), in which the platform was submerged. To test short-term or long-term retention memory, the platform was removed and a probe test was performed immediately after the training phase (day 1) or $24 \mathrm{~h}$ later (day 2), respectively (see Materials and Methods). Immunohistochemistry (IHC) analyses were performed immediately or $24 \mathrm{~h}$ after training. Diagram indicates the PCREB level reduction present during the several stages of the behavioral experiment. The black zones illustrate the proportion of the PCREB after AS-ODN injection. The white zone represents a hypothetical pCREB level, nondeterminate (n.d.) in our study.

\section{Data collection and statistics}

Maze performance was recorded by a video camera suspended above the swimming pool and interfaced with a video tracking system (Ethovision 2.3; Noldus Information Technology). Several parameters of behavioral performance were recorded. During training sessions, the distance swum before reaching the platform was recorded as path length for each trial. During the probe test, two main measures were scored: (1) the time spent in each quadrant of the pool; and (2) the number of annulus crossings and the number of times a mouse crossed the exact, $14 \mathrm{~cm}$ diameter location located at one of the four possible platform positions in the four quadrants. Both of these behavioral variables measure spatial memory, but the number of annulus crossings reveals a more precise search of the platform than the time spent in the four quadrants. In other words, the time spent in the target quadrant can show if mice are able to locate the platform, in an approximate way, and the number of target annulus crossings can determine if mice know the exact position of the platform. We used the number of annulus crossings to calculate an index score of spatial memory, as the difference between the number of crossings of the annulus surrounding the expected position 
of the platform (target, T) and the mean number of crossings of the three remaining annuli (opposite, $\mathrm{O}$; adjacent 1 , A1; adjacent $2, \mathrm{~A} 2)$, divided by the total number of annulus crossings according to the following formula: Index Score $=(\mathrm{T}-(\mathrm{O}+\mathrm{A} 1+\mathrm{A} 2) /$ $3) / T+O+A 1+A 2)$. In addition, the movements of the animals during the probe tests were recorded by using a computerized detection system. The position of the animal was determined five times per second and recorded as $\mathrm{X}$ and $\mathrm{Y}$ coordinates in time. Subsequently, these data were employed to calculate the average swimming speed and the time spent in the maze periphery (13cm-wide wall zone). The SYSTAT 9.0 statistical software package was used for data analysis. For the training phase, the path lengths were averaged for each session (three trials per session) and the session data analyzed with a repeated-measures ANOVA (between factor: treatment, three levels; within factor: sessions, four levels).

During the probe test, the number of annulus crossings was analyzed using a two-way ANOVA with "quadrant" as the within-subjects factor and "treatment" as the between-groups factor. For the quadrant time, we analyzed only the time spent in the target quadrant in the different groups using a one-way ANOVA and not the time in all quadrants of the pool because mice spent the same total time $(60 \mathrm{sec})$ in the four quadrants. Finally, statistical analyses of index, swimming speed, and time spent in the periphery zone of the pool during probe test were performed by using one-way ANOVA. Post hoc comparisons were carried out when allowed, using Scheffe's F-test. All data are represented as means \pm SEM.

\section{Immunocytochemistry checking and image analysis}

To determine the region-specific effect of CREB-AS-ODN, an immunohistochemical analysis of pCREB-immunopositive cells was performed on four experimental groups: (1) the "S-ODN naive" $(n=6)$ and (2) "AS-ODN naive" groups $(n=6)$, in which mice received sense or antisense injection in the CA3 region and were handled daily but remained in their home cage; (3) the "S-ODN trained" ( $n=5)$ and (4) the "AS-ODN trained" groups $(n=6)$, in which mice received sense or antisense injection in the CA3 region and were submitted to the behavioral tests $18 \mathrm{~h}$ later. In this experiment, mice were deeply anesthetized and perfused transcardially with ice-cold $4 \%$ paraformaldehyde in $0.1 \mathrm{M} \mathrm{PB} 20$ or 44 $\mathrm{h}$ after injections. Brains were removed and post-fixed overnight, sectioned $(50 \mu \mathrm{m})$ on a vibratome, and then kept in a solution containing 30\% ethylene glycol, 30\% glycerol, and $0.1 \mathrm{M} \mathrm{PB}$ at $-20^{\circ} \mathrm{C}$ until processed for immunohistochemistry. All solutions contained the phosphatase inhibitor sodium fluoride $(0.25 \mathrm{mM})$. Free-floating sections were rinsed in $0.1 \mathrm{M}$ Tris buffer saline (TBS, $\mathrm{pH}$ 7.4) and incubated with $0.5 \% \mathrm{H}_{2} \mathrm{O}_{2}$ in TBS to inhibit endogenous peroxidase. After blocking in TBS containing 3\% bovine serum albumin (BSA), $2 \%$ normal goat serum, and $0.2 \%$ Triton $\mathrm{X}-100$, tissue sections were incubated for $48 \mathrm{~h}$ at $4^{\circ} \mathrm{C}$ with rabbit primary polyclonal antibodies that recognize the active/ phosphorylated form of CREB (anti-phospho Ser ${ }^{133}$-CREB, rabbit polyclonal antibody, 1:3000; Upstate Biotechnology). After extensive washes in TBS, sections were incubated in biotinylated goat anti-rabbit IgG (1:2000; Jackson Immunoresearch) for $2 \mathrm{~h}$ at room temperature. Sections were again rinsed in TBS followed by incubation in avidin-biotinylated horseradish peroxidase complex (Vectastain Elite kit, Vector Laboratories) for $2 \mathrm{~h}$ at room temperature. Sections were rinsed in TBS and then in TB, and the peroxidase reaction end-product was visualized in $0.05 \mathrm{M} \mathrm{TB}(\mathrm{pH}$ 7.6) containing diaminobenzidine tetrahydrochloride (DAB, $0.025 \%$ ), $0.03 \% \mathrm{H}_{2} \mathrm{O}_{2}$, and $5 \%$ nickel ammonium sulfate for 10 min (Shu et al. 1988). Finally, immunolabeled sections were washed in PB, mounted on gelatin-coated slides, dehydrated, and coverslipped. For each animal, neurons positive for pCREB were counted on both contralateral and ipsilateral sides. The quantification of pCREB-positive nuclei was carried out at $20 \times$ magnification using two to four coronal sections per animal that were averaged for each region (CA3, CA1, and dentate gyrus). The number of positive nuclei was quantified by using a computerized imaging analysis system (Biocom Visiolab 2000 version
V4.50). For the different subfields of dorsal hippocampus, cells were counted at levels corresponding to $1.46-1.94 \mathrm{~mm}$ posterior to bregma in the atlas of (Franklin and Paxinos 1997). Positive pCREB immunoreactive cells were expressed as the number of positive nuclei per $\mathrm{mm}^{2}$. Statistical significance was determined by an ANOVA followed by appropriate post hoc analysis. All data are represented as means \pm SEM.

\section{Acknowledgments}

We wish to thank Tim Goodman and Christopher J. Vecsey for English revision. This study was supported by grants from the Centre National de la Recherche Scientifique (France) and the Universities of Paul Sabatier Toulouse 3 and Bordeaux 1.

\section{References}

Alberini, C.M., Ghirardi, M., Metz, R., and Kandel, E.R. 1994. C/EBP is an immediate-early gene required for the consolidation of long-term facilitation in Aplysia. Cell 76: 1099-1114.

Amaral, D.G. and Witter, M.P. 1995. Hippocampal formation. In: The rat nervous system, 2nd ed. (ed. G. Paxinos), pp. 443-493. Academic Press, San Diego.

Athos, J., Impey, S., Pineda, V.V., Chen, X., and Storm, D.R. 2002. Hippocampal CRE-mediated gene expression is required for contextual memory formation. Nat. Neurosci. 5: 1119-1120.

Bailey, C.H., Bartsch, D., and Kandel, E.R. 1996. Toward a molecular definition of long-term memory storage. Proc. Natl. Acad. Sci. 93: $13445-13452$.

Balschun, D., Wolfer, D.P., Gass, P., Mantamadiotis, T., Welzl, H., Schutz, G., Frey, J.U., and Lipp, H.P. 2003. Does cAMP response element-binding protein have a pivotal role in hippocampal synaptic plasticity and hippocampus-dependent memory? J. Neurosci. 23: 6304-6314.

Bartsch, D., Ghirardi, M., Skehel, P.A., Karl, K.A., Herder, S.P., Chen, M., Bailey, C.H., and Kandel, E.R. 1995. Aplysia CREB2 represses long-term facilitation: Relief of repression converts transient facilitation into long-term functional and structural change. Cell 83: 979-992.

Bennett, M.R., Gibson, W.G., and Robinson, J. 1994. Dynamics of the CA3 pyramidal neuron autoassociative memory network in the hippocampus. Philos. Trans. R. Soc. Lond. B Biol. Sci. 343: 167-187.

Bertaina-Anglade, V., Tramu, G., and Destrade, C. 2000. Differential learning-stage dependent patterns of c-Fos protein expression in brain regions during the acquisition and memory consolidation of an operant task in mice. Eur. J. Neurosci. 12: 3803-3812.

Bito, H., Deisseroth, K., and Tsien, R.W. 1996. CREB phosphorylation and dephosphorylation: a Ca2+- and stimulus duration-dependent switch for hippocampal gene expression. Cell 87: 1203-1214.

Bourtchouladze, R., Frenguelli, B., Blendy, J., Cioffi, D., Schutz, G., and Silva, A.J. 1994. Deficient long-term memory in mice with a targeted mutation of the cAMP-responsive element-binding protein. Cell 79: 59-68.

Bourtchouladze, R., Abel, T., Berman, N., Gordon, R., Lapidus, K., and Kandel, E.R. 1998. Different training procedures recruit either one or two critical periods for contextual memory consolidation, each of which requires protein synthesis and PKA. Learn. Mem. 5: 365-374.

Bozon, B., Davis, S., and Laroche, S. 2002. Regulated transcription of the immediate-early gene Zif268: Mechanisms and gene dosage-dependent function in synaptic plasticity and memory formation. Hippocampus 12: 570-577.

Carew, T.J. 1996. Molecular enhancement of memory formation. Neuron 16: $5-8$.

Colombo, P.J., Brightwell, J.J., and Countryman, R.A. 2003. Cognitive strategy-specific increases in phosphorylated cAMP response element-binding protein and c-fos in the hippocampus and dorsal striatum. J. Neurosci. 23: 3547-3554.

Dash, P.K., Hochner, B., and Kandel, E.R. 1990. Injection of the cAMP-responsive element into the nucleus of Aplysia sensory neurons blocks long-term facilitation. Nature 345: 718-721.

Davis, H.P. and Squire, L.R. 1984. Protein synthesis and memory. Psychol. Bull. 96: 518-559.

Deisseroth, K., Bito, H., and Tsien, R.W. 1996. Signaling from synapse to nucleus: Postsynaptic CREB phopsphorylation during multiple forms of hippocampal synaptic plasticity. Neuron 16: 89-101.

Florian, C. and Roullet, P. 2004. Hippocampal CA3 region is crucial for acquisition and memory consolidation in Morris water maze tasks in mice. Behav. Brain Res. 154: 365-374.

Frank, D.A. and Greenberg, M.E. 1994. CREB: A mediator of long-term memory from molluscs to mammals. Cell 79: 5-8.

Franklin, K.B.J. and Paxinos, G. 1997. The mouse brain in stereotaxic 
coordinates. Academic Press, San Diego.

Frederickson, R.E., Frederickson, C.J., and Danscher, G. 1990. In situ binding of bouton zinc reversibly disrupts performance on a spatial memory task. Behav. Brain Res. 38: 25-33.

Gold, A.E. and Kesner, R.P. 2005. The role of the CA3 subregion of the dorsal hippocampus in spatial pattern completion in the rat. Hippocampus 15: 808-814.

Gonzales, G.A. and Montminy, M.R. 1989. Cyclic AMP stimulates somatostatin gene transcription by phosphorylation of CREB at serine 133. Cell 59: 675-680.

Guzowski, J.F. and McGaugh, J.L. 1997. Antisense oligonucleotide-mediated disruption of hippocampal cAMP response element binding protein levels impairs consolidation of memory for water maze training. Proc. Natl. Acad. Sci. 94: 2693-2698.

Guzowski, J.F., Setlow, B., Wargner, E.K., and McGaugh, J.L. 2001. Experience-dependent gene expression in the rat hippocampus after spatial learning: A comparison of the immediate-early genes Arc, c-fos, and zif268. J. Neurosci. 21: 5089-5098.

Handelmann, G.E. and Olton, D.S. 1981. Spatial memory following damage to hippocampal CA3 pyramidal cells with kainic acid: Impairment and recovery with preoperative training. Brain Res. 217: $41-58$

Hardingham, G.E., Arnold, F.J., and Bading, H. 2001. Nuclear calcium signalling controls CREB-mediated gene expression triggered by synaptic activity. Nat. Neurosci. 4: 261-267.

He, J., Yamada, K., and Nabeshima, T. 2002. A role of Fos expression in the CA3 region of the hippocampus in spatial memory formation in rats. Neuropsychopharmacology 26: 259-268.

Impey, S., Mark, M., Villacres, E.C., Poser, S., Chavkin, C., and Storm, D.R. 1996. Induction of CRE-mediated gene expression by stimuli that generate long-lasting LTP in area CA1 of hippocampus. Neuron 16: 973-982.

Josselyn, A.J. and NGuyen, P.V. 2005. CREB, synapses and memory disorders: Past progress and future challenge. Curr. Drug Targ. CNS \& Neurologic. Dis. 4: 481-497.

Kaang, B.K., Kandel, E.R., and Grant, S.G. 1993. Activation of cAMP-responsive genes by stimuli that produce long-term facilitation in Aplysia sensory neurons. Neuron 10: 427-435

Lamprecht, R., Hazvi, S., and Dudai, Y. 1997. cAMP response element-binding protein in the amygdala is required for long- but not short-term conditioned taste aversion memory. J. Neurosci. 17: $8443-8450$

Lassalle, J.M., Bataille, T., and Halley, H. 2000. Reversible inactivation of the hippocampal mossy fiber synapses in mice impairs spatial learning, but neither consolidation nor memory retrieval, in the Morris navigation task. Neurobiol. Learn. Mem. 73: 243-257.

Lee, I. and Kesner, R.P. 2002. Differential contribution of NMDA receptors in hippocampal subregions to spatial working memory. Nat. Neurosci. 5: 162-168.

-2003. Differential roles of dorsal hippocampal subregions in spatial working memory with short versus intermediate delay. Behav. Neurosci. 117: 1044-1053.

Mayford, M. and Kandel, E.R. 1999. Genetic approaches to memory storage. Trends Genet. 15: 463-470.

McNaughton, N. and Morris, R.G.M. 1987. Chlordiazepoxide, an anxiolytic benzodiazepine, impairs place navigation in rats. Behav. Brain Res. 24: 39-46.

Nakasawa, K., Quirk, M.C., Chitwood, R.A., Watanabe, M., Yeckel, M.F., Sun, L.D., Kato, A., Carr, C.A., Johnston, D., Wilson, M.A., et al. 2002. Requirement for hippocampal CA3 NMDA receptors in associative memory recall. Science 297: 211-218.

Nakasawa, K., Sun, L.D., Quirk, M.C., Rondi-Leig, L., Wilson, M.A., and Tonegawa, S. 2003. Hippocampal CA3 NMDA receptors are crucial for memory acquisition of one-time experience. Neuron 38: 305-315.

Pittenger, C., Huang, Y.Y., Paletzki, R.F., Bourtchouladze, R., Scanlin, H., Vronskaya, S., and Kandel, E.R. 2002. Reversible inhibition of CREB/ATF transcription factors in region CA1 of the dorsal hippocampus disrupts hippocampus-dependent spatial memory. Neuron 34: 447-462.

Quevedo, J., Vianna, M.R., Roesler, R., de-Paris, F., Izquierdo, I., and Rose, S.P. 1999. Two time windows of anisomycin-induced amnesia for inhibitory avoidance training in rats: Protection from amnesia by pretraining but not pre-exposure to the task apparatus. Learn. Mem. 6: 600-607.

Rolls, E.T. and Treves, A. 1994. Neural networks in the brain involved in memory and recall. Prog. Brain Res. 102: 335-341.

Saha, S. and Datta, S. 2005. Two-way active avoidance training-specific increases in phosphorylated cAMP response element-binding protein in the dorsal hippocampus, amygdala, and hypothalamus. Eur. J. Neurosci. 21: 3403-3414.

Sargolini, F., Florian, C., Oliverio, A., Mele, A., and Roullet, P. 2003. Differential involvement of NMDA and AMPA receptors within the nucleus accumbens in consolidation of information necessary for place navigation and guidance strategy, in mice. Learn. Mem. 10: $285-293$.

Shu, S.Y., Ju, G., and Fan, L.Z. 1988. The glucose oxidase-DAB-nickel method in peroxidase histochemistry of the nervous system. Neurosci. Lett. 85: 169-171.

Silva, A.J., Kogan, J.H., Frankland, P.W., and Kida, S. 1998. CREB and memory. Annu. Rev. Neurosci. 21: 127-148.

Stupien, G., Florian, C., and Roullet, P. 2003. Involvement of the hippocampal CA3 region in acquisition and in memory consolidation of spatial but not in object information in mice. Neurobiol. Learn. Mem. 80: 32-41.

Treves, A. and Rolls, E.T. 1992. Computational constraints suggest the need for two distinct input systems to the hippocampal CA3 network. Hippocampus 2: 189-199.

. 1994. Computational analysis of the role of the hippocampus in memory. Hippocampus 4: 374-391.

Wallenstein, G.W. and Hasselmo, M.E. 1997. Functional transitions between epileptiform-like activity and associative memory in hippocampal region CA3. Brain Res. Bull. 43: 485-493.

Wiebe, S.P., Staubli, U.V., and Ambros-Ingerson, J. 1997. Short-term reverberant memory model of hippocampal field CA3. Hippocampus 7: 656-665.

Yin, J.C., Wallach, J.S., Del Vecchio, M., Wilder, E.L., Zhou, H., Quinn, W.G., and Tully, T. 1994. Induction of a dominant-negative CREB transgene specifically blocks long-term memory on Drosophila melanogaster. Cell 79: 49-58.

Yin, J.C., Del Vecchio, M., Zhou, H., and Tully, T. 1995. CREB as a memory modulator: Induced expression of a dCREB2 activator isoform enhances long-term memory in Drosophila. Cell 81: 107115.

Zhang, J.J., Okutani, F., Inoue, S., and Kaba, H. 2003. Activation of the cyclic AMP response element-binding protein signalling pathway in the olfactory bulb is required for the acquisition of olfactory aversive learning in young rats. Neuroscience 17: 707-713.

Zhao, W., Cavallaro, S., Gusev, P., and Alkon, D.L. 2000. Nonreceptor tyrosine protein kinase pp60c-src in spatial learning: Synapse-specific changes in its gene expression, tyrosine phosphorylation, and protein-protein interactions. Proc. Natl. Acad. Sci. 97: 8098-8103.

Received March 13, 2006; accepted in revised form May 23, 2006. 


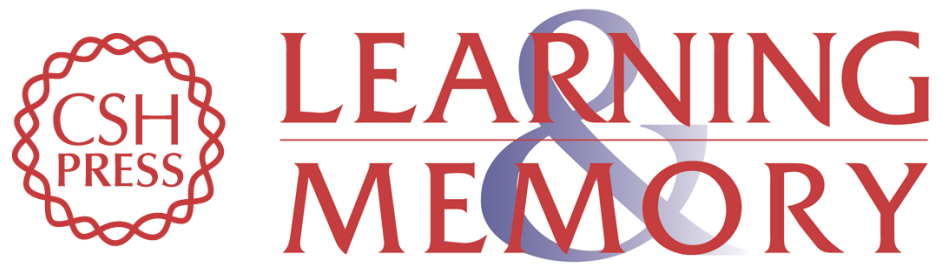

CREB antisense oligodeoxynucleotide administration into the dorsal hippocampal CA3 region impairs long- but not short-term spatial memory in mice

Cédrick Florian, Nicole Mons and Pascal Roullet

Learn. Mem. 2006, 13:

Access the most recent version at doi:10.1101//m.249306

References This article cites 53 articles, 11 of which can be accessed free at: http://learnmem.cshlp.org/content/13/4/465.full.html\#ref-list-1

License

Email Alerting

Receive free email alerts when new articles cite this article - sign up in the box at the Service top right corner of the article or click here. 